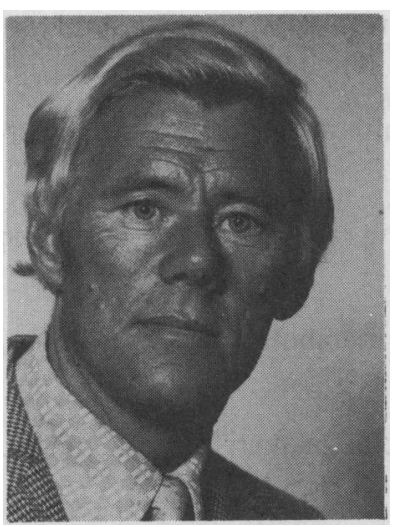

P. Bale

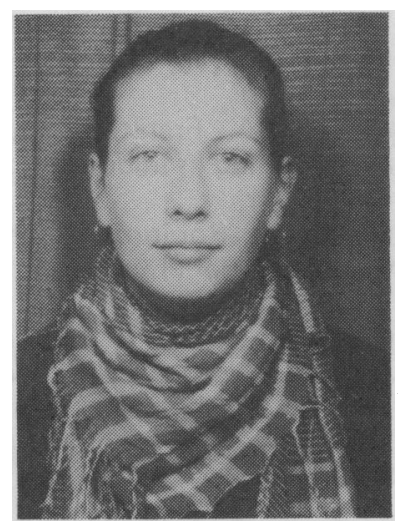

Jacqueline Davies

\title{
EFFECTS OF MENSTRUATION AND CONTRACEPTIVE PILL ON THE PERFORMANCE OF PHYSICAL EDUCATION STUDENTS
}

\author{
P. BALE, PhD and Jacqueline DAVIES, BA* \\ Che/sea School of Human Movement, Brighton Polytechnic, Gaudick Road, Eastbourne
}

\begin{abstract}
Of the 109 specialist female physical education students who answered a detailed questionnaire on menstruation and the contraceptive pill in relation to exercise, $91(83.5 \%)$ reported that they suffered menstrual problems. These included stomach ache, depression, abdominal cramps and backache. Over two-thirds of the students considered that these problems adversely influenced their physical performance. However, whether they had a mainly physiological or psychological effect is not clear. Many of the students with menstrual problems thought that exercise had a beneficial effect and helped alleviate their discomfort. A small number of students reported problems such as amenorrhoea and reduced menses possibly due to excessive training.
\end{abstract}

Just under half the students in the investigation took the contraceptive pill, and though as many students taking the pill complained of menstrual problems as those not taking it, they reported less problems and to a lesser degree. Most students claimed that taking the contraceptive pill had no effect upon their performance.

\section{REVIEW OF LITERATURE}

Various studies of the effects of menstruation on performance suggest that co-ordination is decreased before and during menstruation and is increased immediately after menstruation (Erdelyi, 1962; Shangold, 1980) whereas anaerobic and aerobic work capacity are unaffected during the menstrual cycle (Stephenson et al, 1980). However, the most common effects on sports performance often result from changes in the balance between oestrogen and progesterone before and during the menstrual period. These menstrual problems are known as the "dysmenorrhoea" syndrome. There are

\footnotetext{
*Present address:

Paygate,

Fumers Green,

Nr. Uckfield,

East Essex
}

two sorts of dysmenorrhoea - "spasmodic" and "congestive". Spasmodic dysmenorrhoea usually occurs within an hour or so after the start of bleeding. It manifests itself as spasms of acute cramps in the lower abdomen and sometimes in the back and inner parts of the thighs. Congestive dysmenorrhoea may be felt several days in advance of the menstrual period as a dull aching pain in the upper and lower abdomen accompanied by an increasing "heaviness" and perhaps constipation, nausea and a lack of appetite. There may also be tenderness of the breasts, backache and headaches. Often associated with the pains of dysmenorrhoea is pre-menstrual syndrome characterised by feelings of irritability, depression and lethargy.

On the basis of the above problems it would be expected that sports performance would deteriorate during the pre-menstrual and menstrual periods. Indeed Rougier and Linguette (1962) found evidence of an im- 
pairment of physical performance. Their study of a group of physical education students revealed that $59 \%$ suffered pre-menstrual tension with a corresponding drop in performance levels. A further $1 \%$ who suffered no recognisable pre-menstrual symptoms also showed a definite decrease in performance as regards speed, accuracy, strength and fatigue in the pre-menstrual and menstrual phases.

Zaharieva (1965) carried out a survey of women at the Tokyo Olympics, when competing during a menstrual period. He found that of the sixty-five athletes studied, 27 reported a disturbance in their menstrual function, five athletes reported improvement and thirty-three girls $(51 \%)$ reported no change in their menstrual periods. Depending upon the event, between $50 \%$ and $74 \%$ of the sportswomen retained their form, $1-15 \%$ did worse than expected and $5-20 \%$ did better. In spite of their physical condition, $63 \%$ felt that they had reached their peak form in competition. It is important to point out that, at this top class level of performance, there are many factors which effect performance that are more variable than menstruation itself.

Conversely many athletes have reported relief of some of the symptoms of the pre-menstrual syndrome and less dysmenorrhoea during intensive training (Erdelyi, 1976; Golub, 1959; Shangold, 1980). Very intense training however, may result in a number of unfavourable changes to the menstrual cycle itself. These include irregular periods, secondary amenorrhoea caused by low oestrogen levels and scanty menstrual bleeding. Erdelyi (1976) and Åstrand et al (1963) both reported that between $10-15 \%$ of the sportswomen they studied reported unfavourable changes in menstruation because of sports participation. Other investigators (Anderson, 1979; Webb et al, 1979) have indicated even higher percentages of sportswomen who have reported problems in menstruation possibly due to excessive exercise. Most disturbances were as a result of changes in the characteristics of the menstrual period rather than the course of the cycle.

There appears to be a relationship between the amount of exercise/training and the incidence of menstrual irregularities in which girls who train for the greatest number of hours display the highest percentage of menstrual changes (Webb et al, 1979).

Menstrual problems, particularly secondary amenorrhoea, may be further exacerbated by a low percent body fat (Frisch and McArthur, 1974; Katch et al, 1980).

There is, however, no clear evidence that "normal" exercise causes menstrual dysfunction and it is generally accepted that there is no reason to avoid sports performance before or during menstruation. Indeed, exercise may have both acute and chronic therapeutic effects on some types of menstrual problems for many young women.

\section{THE CONTRACEPTIVE PILL AND ITS RELATION- SHIP TO PERFORMANCE}

Hormone pills can make the incidence of menstruation predictable. In these circumstances the cycle is artificial, and although bleeding occurs, it is not the same as that caused by the break up of the endometrium, as in normal cycles. These artificial cycles are those experienced by the very large number of women who take the contraceptive pill regularly. The various metabolic effects of the contraceptive steroids in the pill suggest that these hormones could alter performance. However, the exact effects of the pill on behaviour are not fully understood. Thus, whether or not the hormones present in the contraceptive pill have the potential for enhancing or interfering with the quality of an individual's performance by altering her strength, co-ordination, timing, endurance or metabolism is not known.

It is also important to remember that there are numerous varieties of combinations of hormonal infertility agents available and they are not identical in their composition. Most doctors prescribing the pill for young women tend to prescribe formulations containing 20 or $30 \mathrm{mg}$ of oestrogen.

\section{PROCEDURE}

The purpose of this study was to investigate the problems, if any, of menstruation on the physical performance of female specialist physical education students and to examine the influence of the contraceptive pill on these problems of menstruation and on performance. A detailed questionnaire was therefore given to first, second and fourth year students at the Chelsea School of Human Movement, Brighton Polytechnic. The third years were on teaching practice when the investigation was in progress. Part I of the questionnaire asked questions on the menstrual cycle and its duration, problems related to the menstrual period and the effects of menstruation on performance. Part II investigated the incidence of taking the contraceptive pill, any side effects associated with taking it, its effects on the problems associated with menstruation and upon performance.

\section{RESULTS}

Of the two hundred questionnaires given to the PE students, 109 were completed and returned. Ninety-one students $(83.5 \%)$ reported that they suffered menstrual problems, the most frequent of which were depression $(57.8 \%)$ and stomach ache $(72.5 \%)$, which are symptoms of congestive dysmenorrhoea. The problems occurred either just before menstruation or in the first days of the period. A small number of students $(7.3 \%)$ reported 
that these problems continued throughout their period and occasionally after menstrual flow had stopped.

Sixty students (55.1\%) complained of abdominal cramps and sixty-one $(56 \%)$ of backache particularly on the first day of the menstrual period. These problems are symptoms of spasmodic dysmenorrhoea.

Seventy-six of the specialist PE students $(69.7 \%)$ considered that menstrual problems affected their performance but whether these problems had a physiological or a psychological effect is not clear. Performance was mainly affected on those days just before menstruation and during the first two days of the period. As Mathews and Fox (1976) comment, physiologically dysmenorrhoea, if not severe, should not hinder performance but psychological factors also play an important role. The effects of menstrual problems on the performance of the students may indeed be more psychological than physiological. When asked why they thought their performance was affected the students complained that they had feelings of lethargy and tiredness, and were disinterested in physical activity. These feelings disrupted their concentration and promoted a "can't be bothered" attitude when related to performance.

Of those students who experienced menstrual problems, two-thirds of them thought that exercise helped to alleviate these problems and only one-sixth considered that exercise made these problems worse. It is generally considered that dysmenorrhoea is probably neither aggravated or cured by sports participation; however, these findings generally support the view that some exercise during the menstrual period is beneficial.

Four students $(3.7 \%)$ reported symptoms of secondary amenorrhoea such as a loss in the regularity of their cycle or an absence of menstruation for three or more months. These students were all training for endurance activities such as cross-country running. $A$ further four students reported that the duration of their menses was reduced and they experienced a lighter blood flow during their competitive season and when they were in training.

The high incidence of menstrual problems reported by the PE students in this study is higher than that reported by other similar studies. However, whether menstrual problems are more common in women who are physically active cannot be confirmed by this investigation because a comparison with non-physically active students was not made.

Of the one hundred and nine PE students who returned the questionnaire 50 girls $(46 \%)$ took the contraceptive pill regularly. This percentage may, however, not reflect the number of PE students taking the pill, since third year students were absent from college when the questionnaires were distributed. It is generally thought that a higher percentage of 20 and 21 year old third year students would take the contraceptive pill than would first and second year students, who made up the large majority of the sample in this investigation.

Though the overall percentage of those students taking the contraceptive pill who complained of menstrual problems, was very similar to those who did not take it, those students taking the pill suffered less problems and to a lesser degree (Table 1). Only a few students were prescribed the progesterone-only pill; most took the combined pill containing oestrogen and progesterone which is in fact more effective in alleviating pre-menstrual and menstrual problems.

Fewer girls taking the contraceptive pill used pain killers to alleviate menstrual problems. Indeed twothirds of the students claimed that these problems had improved and only a few students considered that these menstrual problems had worsened as a direct result of taking the pill.

Considering the various metabolic effects of the pill's contraceptive steroids, it was surprising that no student thought that their performance had deteriorated as a result of taking the pill. Four students $(8 \%)$ claimed that their performance had improved and $46(92 \%)$ said that it had no effect. Only two students regularly took the contraceptive pill in order to avoid menstruating during an important physical performance, another 7 occasionally took it but $41(82 \%)$ never took the pill for this purpose.

One-third of the students complained of side effects from taking the pill. A very small percentage complained of such problems as disruption to their menstrual cycle, migraine, development of varicose veins in the legs, high blood pressure, tiredness and nausea, but the main criticism was that they had put on weight. Half of the students taking the pill experienced a weight gain which may have a detrimental effect on their performance. This weight gain, however, may not necessarily be attributed to the contraceptive pill. Recent studies using placeboes for example, have shown that approximately $20 \%$ of patients experience a measureable weight gain of five pounds or more in the initial stage of placebo taking.

It was interesting to find that $82 \%$ of those students taking the contraceptive pill did not continue taking it for the 28 days of their cycle so that menstruation would not occur. The cycle is completely artificial and ovulation does not take place. Many students, however, felt uneasy about taking it for the full 28 days. They did not enjoy the idea of deliberately missing their menstrual flow which felt "more normal" and reassured some of them that they were not pregnant. 
TABLE I

Menstrual problems and exercise in specialist female physical education students.

Specialist Physical Education Students

1. Reporting menstrual problems

Problems reported: Stomach ache

Depression

Abdominal Cramps

Backache

Fatigue/weakness

Bloated stomach

Loss of co-ordination

2. Menstruation affected their performance:

3. Used pain killers to alleviate their menstrual problems: always

occasionally never

4. Exercise helped alleviate the menstrual problems

5. Exercise made the menstrual problems worse
Not taking the Contraceptive
Pill: $59(54.13 \%)$

Pill: 59 (54.13\%)

$\begin{array}{rr}49 & 83.1 \\ 46 & 78.0 \\ 35 & 59.3 \\ 34 & 57.6 \\ 34 & 57.6 \\ 32 & 54.2 \\ 29 & 49.2 \\ 6 & 10.2\end{array}$

45

8

33

17

40

11

76.7

13.6

55.9

28.8

67.8

18.6
Taking the Contraceptive
Pill: $50(45.87 \%)$

$$
\text { Pill: } 50(45.87 \%)
$$

f

Total

f $\%$

84

32

28

26

25

21

16

and to a lesser degree than students not taking the pill. The major criticism of taking the contraceptive pill was an associated gain in weight though, as stated, it is difficult to lay all the blame on the pill for this.

\section{ACKNOWLEDGEMENT}

We would like to express our thanks to Dr. Mary Wigfield of the Eastbourne Family Planning Association for her help in preparing this paper.

considered that it had no effect upon their performance many suffered less problems during menstruation

\section{REFERENCES}

Anderson, J. L., 1979 "Women's sports and fitness programs at the US Military Academy". Physician and Sports Med. 7: 72-82.

Åstrand, P.-O., Eriksson, B. O., Nylander, I., Engstrom, L., Karlberg, P., Saltin, B., Thoren, C., 1963 “Girl swimmers with special reference to respiratory and circulatory adaptation and gynaecological and psychiatric aspects". Acta Paediatrica Suppl. 147.

Erdelyi, G. J., 1962 "Gynaecological survey of female athletes". Journal of Sports Medicine and Physical Fitness 2: 174-179.

Frisch, R. and McArthur, J., 1974 "Menstrual cycles: fatness as a determinant of minimum weight for height necessary for the maintenance or onset". Science 185: 949-951.

Golub, L. J., 1959 "A new exercise for dysmenorrhoea". American Journal Obst. and Gynec. 78: 152-155. 
Katch, F. I., Katch, V. L., Behnke, A. R., 1980 “The underweight female”. Physician and Sport Med. 8: 55-60.

Mathews, D. K. and Fox, E. L., 1976. The Physiological Basis of Physical Education and Athletes. W. B. Saunders Co.

Rougier, G. and Linquette, Y., 1962 “Menstruation and physical exercise". Presse Medicale 70: 1921.

Shangold, M. M., 1980 “Sport and menstrual function”. Physician and Sports Med. 8: 66-70.

Stephenson, L. A., Kolka, M. A., Wilderson, J. E., 1980 "Anabolic threshold, work capacity and perceived exercise during the menstrual cycle". Med. Science Sports Exercise 12: 87.

Webb, J. L., Millan, D. L., Stolz, C. J., 1979 “Gynaecological survey of American female athletes competing at the Montreal Olympic Games". Journal Sports Medicine and Physical Fitness 19: 405-412.

Zaharieva, E., 1965 "Survey of sportswomen at the Tokyo Olympics". Journal of Sports Medicine and Physical Fitness 5: 215-219.

\section{BOOK REVIEW}

Title: $\quad$ EXERCISE PHYSIOLOGY: PHYSIOLOGIC BASES OF WORK AND SPORT

Author: Jurgen Stegemann, translated and edited by James S. Skinner

Publishers: $\quad$ George Thieme; Verlag Stuttgart \& New York. Year Book Medical Publishers Ltd.

Price: $£ 9.75 \quad 345$ pages 197 figs. . Soft cover

This is the first textbook on exercise physiology to appear in the popular Year Book series published in the 'Pocket Book' format. This translation of Professor Stegemann's book communicates the essential physiology, underlying the study of exercise, in a crisp and clear manner without unessential repetition. However because it is a translation of the 1976 German second edition of the 1971 publication then the exercise physiology is as expected, a bit dated. The contents of this book cover the range of topics expected in a book on exercise physiology and they include the essential physiology of muscle cell function through to altitude and diving physiology. There is a chapter on what is called "biologic cybernetics" which is simply control theory used to explain selected physiological principles of regulation. In another section there is a description of an on-line system for the determination of oxygen uptake which has been called "computer controlled spiroergometry". This information would have been welcomed in the middle 1970's but these systems have been available commercially for some time and occupy pride of place in many exercise physiology laboratories.

Dr. Skinner has been loyal in his translation of the German text as is reflected in his use of terminology which he does not use in his own writing. For example Professor Stegemann refers to muscle as being made up of red and white fibres and that with endurance training white fibres are converted into red fibres. The distinction between red slow twitch fibres and red fast twitch fibres has not been made. The nomenclature describing both populations of fibre types and the limited conditions under which this conversion takes place are well known to exercise physiologists in general and Dr. Skinner in particular.

Professor Stegemann does use much of his own work and that of his colleagues to describe and illustrate the physiological changes which occur during exercise and so this does present the reader with the opportunity to see research results which have previously only appeared in German language journals. Although there is no bibliography section in the book, each illustration containing published research work is adequately referenced. The sections in the book which may attract those of us interested in the mechanisms underlying improvements in performance, are most disappointing because they offer attractive headings to various sections, which in reality have nothing new to say. Therefore in one sense this translation of what has effectively been the course textbook for the students at the Cologne Sports School, is reassuring in that it confirms that the principles and concepts in human exercise physiology are indeed international. This translation has not unlocked a wealth of "unique information on work physiology and sport physiology" as the publishers claim but simply reminded us of what we were teaching a decade ago. Even at this modest price of $£ 9.75$, Astrand and Rodahl can rest easily; there is no contest!

Clyde Williams 